\title{
A Learning Development team: three developers, one pedagogy
}

\author{
Pamela McKinney \\ University of Sheffield, UK \\ Jamie Wood \\ University of Sheffield, UK \\ Sabine Little \\ University of Sheffield, UK
}

\section{Abstract}

With the inception of Centres for Excellence in Teaching and Learning (CETLs), the demand for learning developers has increased in many institutions across the UK. Operating largely in small teams, yet within the remit of facilitating large-scale institutional change, CETLs often find themselves outside established institutional structures, with developers fulfilling newly defined roles and responsibilities. This short paper focuses on the way learning development support has been integrated in one particular CETL, the Centre for Inquiry-based Learning in the Arts and Social Sciences based at the University of Sheffield. The paper explores the issues, challenges and experiences that are part of the 'Learning Development and Research Associate' role in relation to supporting staff and students in the development of Inquiry-based Learning (IBL) pedagogies, often through the use of collaborative inquiry approaches. It is suggested that the strength and benefits of the LDRA role lie in its blended nature, the emphasis which is placed upon brokering support across the team and the institution as a whole, and the centrality of the inquiry approach to the way in which the position of LDRA has developed.

Keywords: learning development; inquiry-based learning, team 


\section{Introduction: The CILASS context}

CILASS, the Centre for Inquiry-based Learning in the Arts and Social Sciences, based at the University of Sheffield, is one of 74 'Centres for Excellence in Teaching and Learning' funded by the Higher Education Funding Council for England (HEFCE) in 2005 as part of a 5 year programme of learning and teaching enhancement at UK HE institutions. The CETL programme recognised existing excellence in teaching practice; in the case of CILASS this related to the use of inquiry-based pedagogies at the University of Sheffield, particularly in the faculties of Arts and Social Sciences. Inquirybased Learning (IBL) is a term used to describe a broad spectrum of approaches to learning that are based on a process of self-directed inquiry or research and has often been proposed as a means of engaging students explicitly with the processes of knowledge creation, facilitating the development of dispositions and capabilities that are particularly relevance for life and work in today's complex world (Brew, 2006).

CILASS funding is currently employed to finance two main streams of curriculum development activity and associated evaluation, research and dissemination: departmental programmes of curriculum development in the faculties of Arts and Social Sciences; and IBL grant projects that are smaller scale curriculum development, Scholarship of Teaching and Learning or inquiry projects taken forward by individuals or small teams of academic staff (and, in one case, students) from across the University. In order to facilitate these developments, the CETL employs three 'Learning Development and Research Associates' (LDRAs) in IBL who each have their own specialism (Information Literacy, Networked Learning and Dissemination respectively) and share the load of development support. Whilst many CETLs have created additional posts for learning developers and learning technologists, only a fraction of these operate within one particular pedagogical approach. This presents additional challenges as well as additional rewards. This article briefly outlines the pedagogical and professional context, describes the roles of the three LDRAs, before exploring how cross-brokering of knowledge and skills helps to provide coherent development support for IBL at the institution. 


\section{Working within one pedagogical context}

IBL positions students at the centre of their own learning, inviting them to formulate questions, design their own research and investigations, and explore possibilities without necessarily needing to supply a 'correct answer'. An open-ended approach to tasks given by tutors means a variety of solutions and responses are possible (Khan and O'Rourke, 2005). Learning through IBL can involve active, self-directed and taskbased learning and original student-designed research. Inquiry is often a collaborative activity and features the development of information literacy capabilities through active engagement with information searching, evaluation and presentation. This allows students to build up a wide range of transferable skills as part of their degree, such as communication, teamworking and technical skills. New technologies are often utilised in order to facilitate research or online collaboration. The implementation of a programme of educational development with one particular pedagogical approach has helped to create an institutional community which shares a language for learning design and pedagogical thinking. (CILASS, 2007d) For the LDRAs, the pedagogical focus makes it easier to support a large variety of projects, as the common denominator facilitates the exchange of information with other staff, the organisation of communitybuilding events, and the design of pedagogical resources (Little, 2008a).

\section{The LDRA blended role}

The role of 'Learning Development and Research Associate' within the CILASS core team is a blended role that involves pedagogical and other support for curriculum development, project and programme evaluation and research. Although the post was created specifically for the CETL, the role description largely corresponds with the work of Surrey and Robinson (2001), who researched and analysed 449 job adverts in the area of educational technology and support. Their analysis identified requirements ranging from teaching to dissemination, as well as research, knowledge of new technologies, and managerial and administrative skills. To circumvent potential issues surrounding the image of 'Jack of all trades, master of none', each LDRA has a 
specialist area: Networked Learning, Information Literacy and Dissemination. The first two roles were included in the CILASS team from the beginning of the programme and the latter was added in 2006. In addition to these requirements, the role of the LDRA includes that of brokering of expertise between academic project leaders and professional services staff in the Learning \& Teaching Services department (LeTS), the Library, Audio/Visual Services and Corporate Information and Computing Services (CICS), to ensure that projects run as smoothly as possible. The role of 'broker' is defined by the OED (2008) as: 'A middleman, intermediary, or agent generally; an interpreter, messenger, commissioner'.

Of these descriptors, 'intermediary' is probably closest to how the LDRAs view this sphere of their activities, which involve identifying where in the institution the particular technical or pedagogic expertise lies and bringing that expertise to bear on the project in hand. CILASS funding can smooth this process with colleagues outside the core team, but often a process of negotiation over project time and resource commitment has to take place before engagement can be secured fully. On this issue, there seems to be congruence with the findings of Slack et al (2004), whose report on the subject of how brokerage works in communities and the workplace suggests that although the term 'brokerage' defies simple definition, and that the credibility of a broker relies on their understanding of the working context of their colleagues. The value of a broker, they state is in 'providing new pedagogical and curricular approaches.' (Slack et al, 2004). Handal (2008) identifies the academic developer as belonging to at least two communities - on the one hand the community of academic development, in which they are full participants, on the other hand the wider academic community, with which they might only marginally connect, playing a small but vital role in the larger educational context. Wenger (1998) describes the brokering role as a boundary trajectory, linking several communities of practice and spelling a delicate challenge for the developer.

The three LDRAs have varied experiences to bring to the team, for example through school teaching, professional roles such as librarian, and Masters and PhD study in a number of subjects, and as academic teaching staff. None of the LDRAs has previously 
worked as an educational developer and the wide variety of knowledge and skills required by the role has ensured a steep learning curve. The LDRA role is a novelty in the institution and a degree of flexibility in defining our approach to educational development has been a feature of activities to date. Project evaluation responsibilities are shared with the project leaders, with LDRA support focussed at the start of the process, in the establishment of an evaluation framework and plan. Project leaders take a greater degree of responsibility for the collection of evaluative data from students, although sometimes this is facilitated by the LDRA, for example in the running of focus groups. CILASS has adopted and expanded the Theory of Change evaluation approach (Connell and Kubisch, 1998), combining it with Enabling, Process and Outcome Indicators. Through backward-mapping, project leaders identify the activities necessary to achieve their intended outcomes, and realise where potential barriers and enablers are situated within their context. This method, whilst work intensive, allows personalised evaluation and ownership on the project leader's part. Occasionally, either learning development or evaluation support lead to joint research and/or publication between project leaders and LDRAs, further broadening the role beyond previous similar posts in the institution. The specialist roles for the three LDRAs are discussed below

\section{Information Literacy}

There are various definitions of information literacy (IL) in use worldwide but one of the most often cited is that developed by the American Library Association (1989):

To be information literate a person must be able to recognise when information is needed and have the ability to locate, evaluate and use effectively the needed information.

The skills of searching for information, particularly in the electronic environment are essential for University students, but it is the so called 'higher order' conceptions of information literacy such as critical thinking, evaluation and synthesis (Bruce, 1997a) that are particularly important for students to be effective inquirers. Academics can have 
very varied conceptions of what information literacy means (Bruce, 1997b) and the use of information and what it means to be information literate is dependent on the subject discipline (Boon et al., 2007). The Society of College, National and University Libraries (SCONUL) 'Seven Pillars' model of information literacy (1999) is used in the University and by CILASS to define the scope of Information Literacy that should be addressed in a University education. The model describes abilities from recognising an information need (Pillar 1) through constructing search strategies, searching for and accessing information (Pillars 2, 3 and 4) to comparing and evaluating information (Pillar 5), organising, applying and communicating information (Pillar 6) and synthesising and creating new knowledge (Pillar 7).

Some academic staff are familiar with the term 'information literacy' and project proposals can be very specifically aimed at building IL through IBL. However it can be the case that the project proposal does not explicitly discuss information literacy but still involves students developing IL skills, or sometimes a focus on IL is not particularly appropriate within a project context. The Seven Pillars model can be very useful as a tool to initiate discussions with project leaders about the scope and depth of the field of information literacy. Often activities that build what an information professional might label 'information literacy' are given alternative labels such as 'study skills' or 'research skills'. The challenge for the LDRA (Information Literacy) is to work with project leaders to determine existing departmental strategies for building IL competencies and to recommend suitable IBL strategies for the project context that build IL skills to support inquiry. This can mean brokering support from colleagues in the Library, for example, to develop electronic resource lists to support IL and the provision and tailoring of online information skills tutorials that are made available through the Virtual Learning Environment.

\section{Networked learning}

CILASS adopts a definition of Networked Learning which largely corresponds with that reported by Jones (2004): 
Networked learning is learning in which information and communication technology (C\&IT) is used to promote connections: between one learner and other learners, between learners and tutors; between a learning community and its learning resources. (p. 89)

Within these parameters, IBL often takes the form of Collaborative Inquiry, using technology to facilitate collaboration and tutor support between face-to-face sessions. Only on rare occasions is technology used as a substitute for face-to-face teaching, more often it is intended as a means for students to engage with the content in advance of or between sessions, leaving face-to-face sessions for more inquiry-based activities.

Whilst some project leaders approach their work with clear pedagogical design in mind, networked learning support can and does include an ongoing struggle to ensure technology is not adopted for technology's sake, but instead is tied to a solid IBL approach. At the same time, however, there is the lure of new technologies, and visions of how they might be used in IBL, leading to a number of innovative ideas which, as they have not been attempted before, can lead to various levels of success. In an environment strongly shaped by student evaluations and examination results, support will take place in a fine balance between encouraging innovation and maintaining or improving the departments' record of achievement. CILASS funding can help here to create the space for pilot cases, which are then taken on board by the department in future years. In terms of technology, this can be particularly viable through funding of software or hardware to support IBL. Support from the University's Learning and Teaching Services (LeTS) often provides both a further opinion of the project (as the unit has its own educational developers), as well as the technical skill to produce videos, set up virtual learning environments, design web pages or identify additional technologies necessary to support a particular project. The brokering role is further discussed below. 


\section{Dissemination}

As the CILASS programme has progressed, increasing emphasis has been placed upon the need to share learning from projects in order to ensure that CETL supported teaching and learning initiatives have maximum impact at the University and beyond. There are two strands to this - CILASS authored or directed dissemination activities and those which project leaders engage in themselves. Initially, significant resource was devoted to running events, and setting up informal and formal special interest groups. This was intended to facilitate the development of IBL communities of practice (Wenger, 1998) and the sharing of good practice. More recently, the emphasis has shifted to the production of more formal, written pieces for publication and distribution to stakeholders and externally, although some early CILASS projects have already reported through HE Academy Subject Centres and the scholarly press (Verbaan, 2008; Semmens and Taylor, 2006; van Oostrum \& Steadman-Jones, 2007; Carson, 2007; Stafford \& Martin 2007; Stafford, 2008).

Over the past months CILASS has been developing case studies for a number of completed projects. These are discussed in greater detail and links to relevant materials are provided in "Design for Inquiry-based Learning Case Studies" (Wood, 2009) in this issue. In general terms, the cases provide practitioners with a range of resources that illustrate ways in which IBL is being designed and facilitated in CILASS projects. They are presented via a website to provide greater flexibility for searching and analysis than would be possible with paper-based cases. By putting the cases on-line we can share a far wider range of resources, including multimedia materials, and we are able to exploit the possibilities of on-line interaction through the use of web 2.0 technologies. The central part of each case study is what we have termed an IBL 'design overview'. This document, which is standardised across projects, gives an informative guide to the context from which the project emerged, the IBL activities in which students engaged, the support which they received from staff, and some feedback from staff and students about their experiences. Because a uniform template was created for the design overview, we (and the users of the website) can more easily abstract and compare 
projects. The range of resources which accompany the design overview is large (photos, videos, podcasts, student work, staff evaluations and reflections, course documentation, journal articles, blog postings) and enables those who visit the website to get a richer impression of the project than is possible in a solely textual format. Additional dissemination activities have included the development of the CILASS newsletter, crucIBL, the production of a series of briefing papers which focus upon the key outcomes and achievements of the CILASS programme so far. References and weblinks for these publications are available in the bibliography.

\section{Brokering within the team}

In the very first round of departmental funding, the LDRA assigned to each project was identified by gauging the amount of Information Literacy or Networked Learning that was inherent in each individual project strand - in reality, however, this was not sustainable, as it necessitated detailed knowledge of every single department strand by each LDRA. Work is now divided by departmental programme, with brokering of expertise between LDRAs taking place where necessary. Sometimes this might involve a short, informal conversation between LDRAs or an exchange of emails, but on other occasions it can involve more extended brokered direct contacts with project leaders. For example the first departmental project in the School of Law had a significant focus on Networked Learning so the Networked Learning LDRA took responsibility for the support. However it became apparent as the project developed that one of the objectives was to develop IL competencies in students so the Information Literacy LDRA was consulted about the best ways to take this aspect of the project forward. Sometimes, the 'brokered' LDRA becomes the main support contact with the project leader, and this can be due to the subject area appealing more to the interests and experience of a particular LDRA - for example, the LDRA for dissemination has a background in historical research and so took on support for the History Department.

In a fast-moving, busy environment, it can often appear easier to attempt to facilitate a project as a whole, neglecting the brokering role. With each brokering, an additional 
element of complexity and member of staff is added to the team, resulting in more avenues to pursue and to keep track of (Little, 2008b). However, brokering the real experts can only ever benefit the project, so a constant effort is made to ensure each project support team is tailored specifically to its needs, co-ordinated by the department's lead LDRA, although individual strands might devolve to another LDRA in the team.

\section{Conclusion}

In conclusion, the generic LDRA role involves providing a wide variety of support for project leaders and a significant degree of support for each other so that the pedagogical and strategic aims of CILASS can be achieved. The 2007 Interim Evaluation Report, based on data collected from project level evaluations and key stakeholders in the University provides some insight into the institutional impact of the CETL. The report (CILASS, 2007d: 10) highlights the generally positive impact that the CILASS programme has had on the student experience. Outcomes identified include: 'increased engagement, confidence and responsibility in relation to learning; improved information literacy and IT skills; enhanced awareness of the inquiry/research process and of the role and value of inquiry within the wider social context'. High quality pedagogical support and intensive facilitation provided by the CILASS team is cited as being greatly appreciated by the institution.

All three of the LDRAs have to manage the tension between the requirements of academic project leaders and those of CILASS. There can be a gap in understanding between what a project leader expects a project to entail and the activities that CILASS expects all project leaders to undertake. This is rarely a problem for the curriculum development side of projects because the implementation of IBL initiatives in teaching and learning situations is often the primary focus of the project plan and has an immediacy that longer term aspects of the project may seem to lack. However ensuring engagement with evaluation and dissemination can be more problematic for the LDRA. 
The pedagogical focus on Inquiry-based learning lends itself to the creation within and beyond the core team of an inquiry-based approach to educational development, evaluation and dissemination. For example the LDRAs are taking a reflective and inquiring approach to their own practice through engaging in scholarly activities such as literature review, a reflective blog and writing for publication, whilst the activities in which we engage with staff and students are almost exclusively based on inquiry-based approaches. In addition the LDRAs are all registered on the SEDA (Staff and Educational Development Association) Fellowship scheme which requires participants to demonstrate a scholarly approach to their roles. It is beyond the scope of this paper to discuss whether the larger CILASS community is as engaged with the ethos of inquiry as the LDRAs are, although evidence of an inquiry approach to teaching can be seen through the creation of a special interest group of academic staff and developers from the CILASS community who are taking forward a collaborative writing project in the field of the Scholarship of Teaching and Learning. What can be stated with some confidence, however, is that the inquiry approach underpins every aspect of the LDRA role itself. The balancing of the needs of the project and the needs of the CILASS team can be challenging, but ultimately the opportunity to work with such a diverse group of people within such a coherent pedagogic framework offers significant personal and professional rewards.

\section{References}

Boon, S., Johnston, B. \& Webber, S. (2007): 'A phenomenographic study of English faculty's conceptions of information literacy'. Journal of Documentation 63 (2) p. $204-228$

Brew, A. (2006): Research and teaching: beyond the divide. Basingstoke: Palgrave MacMillan. 
Bruce, C. (1997a): 'The relational approach: a new model for information literacy'. The New Review of Library and Information Research, 3, 1-22.

Bruce, C. (1997b): The seven faces of information literacy. Adelaide: Auslib Press

CILASS (2007a): 'Student Partnership in Educational Development'. CILASS Briefing Papers 001 [ONLINE] https://portal104.shef.ac.uk/content/1/c6/07/93/44/Briefing\%20Paper\%20001.pdf accessed 14/05/08

CILASS (2007b): 'CILASS Achievements 2005-2007'. CILASS Briefing Papers 002 [ONLINE]

https://portal104.shef.ac.uk/content/1/c6/07/93/44/Briefing\%20Paper\%20002.pdf accessed 14/05/08

CILASS (2007c): CruclBL: a melting point for inquiry-based learning. Issue 1, December 2007 [ONLINE]

https://portal104.shef.ac.uk/content/1/c6/07/93/44/J22144\%20cruclBL\%20Newslett er.pdf accessed 14/05/08.

CILASS (2007d): Interim evaluation report, July 2007. [ONLINE] http://www.shef.ac.uk/content/1/c6/04/89/91/CILASS\%20Interim\%20Evaluation\%2 OReport\%20July\%202007.pdf accessed 14/05/08

CILASS (2008): 'Learning Spaces' CILASS Briefing Papers 003 [ONLINE] http://www.shef.ac.uk/content/1/c6/07/93/44/J24045 Briefing.pdf accessed $14 / 05 / 08$

Connell, J. \& Kubisch, A. (1998\}: 'Applying a Theory of Change approach to evaluating comprehensive community initiatives', in K. Fulbright-Anderson, A. Kubisch \& J. 
Connell (Eds), New approaches to evaluating community initiatives Vol 2 (pp. 1544). New York: The Aspen Institute.

Handal, G (2008): 'Identities of academic developers: critical friends in the academy?' in R Barnett and R DiNapoli (eds) Changing Identities in Higher Education: Voicing Perspectives. Abingdon: Routledge, pp. 55-68.

Jones, C (2004): 'Networks and learning: communities, practices and the metaphor of networks' in ALT-J, Research in Learning Technology, Vol 12, No 1, pp 81-93

Khan, P. and O'Rourke, K. (2004): Guide to curriculum design: enquiry-based learning. York, Higher Education Academy, Imaginative Curriculum Network. [ONLINE] http://www.heacademy.ac.uk/assets/York/documents/resources/resourcedatabase/ id359 guide to curriculum design ebl.rtf [accessed 16/05/08].

Little, S (2008a): 'The role of the developer in institutional change: Tales from the edge'. Proceedings from Networked Learning Conference, Halkidiki, Greece, May 2008, pp. 245-252.

Little, S (2008b): 'Oily Rag or Winged Messenger: The role of the developer in multiprofessional teams', in R Donnelly and F McSweeney (eds): Applied E-Learning and E-Teaching in Higher Education. Hershey, PA: IGI Publishing

Oxford English Dictionary Online $2^{\text {nd }}$ ed. (2008): Oxford University Press.

SCONUL (1999): Information skills in higher education: a SCONUL position paper [ONLINE] http://www.sconul.ac.uk/groups/information literacy/seven pillars.html accessed 14.05.08 
Semmens, N. and Taylor, M. (2006): 'CILASS: promoting inquiry-based learning and information literacy'. UK Centre for Legal Education Newsletter (Directions), Spring. [ONLINE] http://www.ukcle.ac.uk/directions/previous/issue12/cilass.html accessed 21/05/08

Slack, K. Thomas, L., Quinn, J., Casey, L., Vigurs, K., and Flynn, N. (2004): Learning brokerage: Building bridges between learners and providers. London: Learning and Skills Development Agency. [ONLINE] http://www.citizensonline.org.uk/site/media/documents/1034 Learning\%20brokers \%20report\%20-\%20workplace1626.pdf accessed 27/10/08

Stafford, T. (2008). 'A fire to be lighted: a case-study in enquiry-based learning'. Practice and Evidence of Scholarship of Teaching and Learning in Higher Education, 3 (1), 20-42. [ONLINE] http://www.pestlhe.org.uk/index.php/pestlhe/article/view/39/160; accessed 29/4/2008

Stafford, T. \& Martin, C.J. (2007). 'How to do a neuroscience lab class with 120 students'. HEA Psychology Network Newsletter, Issue 45 November 2007 [ONLINE] http://www.psychology.heacademy.ac.uk/docs/pdf/p20071127 issue45.pdf access ed $14 / 05 / 08$

Surry, D., \& Robinson, M. (2001): 'A taxonomy of instructional technology service positions in higher education'. Innovations in Education and Teaching International, 38(3), 231-238.

van Oostrum, D., Steadman-Jones, R., Carson, Z. (2007): 'Taking the Imaginative Leap: Creative Writing and Inquiry-Based Learning'. Pedagogy, 7 (3), 556-566. 
Verbaan, E. (2008): 'The Multicultural Society in the Netherlands. Technology-supported Inquiry-based Learning in an Inter-Institutional Context'. Teaching in Higher Education, 13 2008, 437-447.

Wenger, E. (1998). Communities of practice : learning, meaning, and identity. Cambridge:

Wood, J. (2009). 'Design for Inquiry-based Learning Case Studies'. Journal of Learning Development in Higher Education 1, 2009.

\section{Author details}

Pamela McKinney has a background as an information professional and is a chartered member of CILIP: the Chartered Institute of Library and Information Professionals. She is a Learning Development and Research Associate at CILASS (Centre for Inquiry-based Learning in the Arts and Social Sciences) and is responsible for taking forward the information Literacy strand of CILASS development and research activity.

Sabine Little currently works for CILASS (The Centre for Inquiry-based Learning in the Arts and Social Sciences), a HEFCE-funded CETL based at the University of Sheffield. She holds the position of Learning Development and Research Associate, specialising in support for networked learning and working with staff to incorporate inquiry-based learning (IBL) into their teaching. She also facilitates the Student Ambassador Network.

Jamie Wood is a Learning Development and Research Associate at CILASS (Centre for Inquiry-based Learning in the Arts and Social Sciences) with responsibility for 
taking forward the CILASS dissemination strategy. Jamie works with project leaders to develop case studies of IBL curriculum development projects and writes CILASS briefing papers and newsletters. 